and somewhat tender on palpation. The losses continued for the space of a fortnight and then ceased, but the patient was still in a low state. She gradually became stronger until the beginning of February of the present year, when the uterus was about the size of a cricket-ball, and she would be about three months advanced in pregnancy. At this time a niece, who had only parted from her two days previously, and to whom she was much attached, committed suicide by drowning herself in the river, for no apparent cause. The news of this acted upon Mrs. Cas a severe shock. I was summoned to her, and found her in a state of great collapse, from which she was with great difficulty aroused, and did not wholly come out of it for several days. Small hæmorrhagic discharges were now of daily occurrence from the womb, and examination showed that the womb was enlarging and the os slightly ulcerated. By the administration of ergot and tannin, alternated with iron and acetate of lead, the hæmorrhage was checked, but kept breaking out at intervals of a fortnight or so.

On the morning of Aug. 5th the woman had pains, which proved to be labour pains, accompanied with great loss of blood, and at 5 A.M. she passed a mass, which upon examination proved to be the degenerated fotus and placentaone mass of fat and globules. Upon examination, the interior of the uterus was found to be covered with soft, adherent particles similar to the mass which had been extruded. These were removed with the finger and the parts well washed out with Condy's fluid and water, and absolute rest enjoined. The case has since run an altogether normal course, no bad symptoms having arisen.

This case was extremely puzzling to diagnose; several examinations were made, externally and per vaginam, but nothing definite could be made out, and the last examination, conducted on the day prior to the confinement, led me to think that it was a case of placenta prævia; but the uterus, though large, was easily and perfectly malleable, very soft, no tumour such as fibroid or anything of a like nature to be discovered, and the only diagnosis, the correct knowledge of the state of affairs, was furnished by nature when the mass was expelled. From the early examination I was led to think that all would have gone well had not the system received so rude a shock by the sudden announcement of the suicide of her niece.

Thetford, Norfolk.

\section{ON A}

\section{CASE OF SUDDEN UNEXPECTED DELIVERY IN A PRIMIPARA.}

BY Worsley J. HARRIS, M.R.C.S., L.R.C.P., \&c.

CASES of very rapid delivery with no symptoms of any kind to give warning of the approach of labour are sufficiently rare to be worthy of record. I think the following case will be interesting in showing how rapidly and unexpectedly the uterus, without any apparent reason for so doing, will empty itself of its contents.

Mi. Cabout five feet three inches in height, well developed muscles, broad hips, and pelvis shallow and capacious, was, according to her own reckoning, eight calendar months pregnant, and expecting delivery in a month's time. One morning at 10 A.M., while doing her usual routine of house work, which was that of a woman in the lower ranks of life, she felt sick and giddy, so went up into her bedroom to lie down. After lying for about five minutes she was seized with an irresistible desire to defecate, and rushing to a night stool in the adjoining room was immediately delivered of a small but well-formed male child. There being no one in the house, she severed the cord, but left the child in the commode, and then went and lay down. No one came to the house for an hour, when, the baker's boy calling, she asked him to run for a friend, an old midwife, who came and took away the placenta. The case occurring in the country, and some five miles away, I did not get the message until 4 P.M. When I got to the patient's house I found the girl undressed and in bed, and in every way doing well. The uterus contracted; no hæmorrhage; no laceration of perineum. In the night stool was a well-formed but small male child, situated with its head downwards, the occiput anterior and inclined slightly towards the left side of the commode, with forehead posterior and to the right. The shoulders, too, presented in the left oblique diameter of the night stool (if I may be allowed to use that expression); the thighs and knees were flexed. There was about a pint and a half of mixed blood and liquor amnii, in which the child's head and face were buried. I found the placenta entire and healthy in s separate utensil.

Post-mortem examination of the child.-Sixteen inches long, four pounds and a half in weight. The child slightly but beautifully formed; no marks of bruising or injury anywhere; dark hair on head; no membrana pupillaris; pupil midway between contraction and dilatation; face and lips somewhat blue and congested ; nails formed, and reaching to the tip of the fingers and toes; umbilicus between a quarter to half an inch nearer to the pelvis than to the ensiform' cartilage; the liver, heart, spleen, and kidneys were normal; the lungs were perfectly consolidated, without the slightest sign of an air-vesicle; with various trials they sank in water.

I think that the position in which the child was situated in the night stool goes a long way to prove the truth of the mother's story. For it is not at all likely that the mother, and especially an inexperienced woman as this one was, would have placed the child in such a truly natural position. And then, again, the tendency of the occiput to the left and forehead to the right and the position of the shoulders in the left oblique diameter (so allow me to call it) of the night stool would seem to point to the fact that the child presented originally in the first cranial position, and that it had passed through the parturient canal without any decided rotatory or adaptive movements, and this would be for the most part likely to occur in a case with rapid and strong uterine contractions, and a broad, shallow, roomy pelvis. The post-mortem examination showed that the child was about an eight months' foetus; it was in every respect well formed, and if it had been given a chance to breathe it would probably have lived.

Blackheath.

\section{A STRANGE CASE OF MALINGERING.}

\section{By GEorge Thorpe, L.S.A. Lond., \&c.}

M. C_- aged seventeen, a plump healthy-looking country girl, in service in a ninister's family, was brought to me by her mistress, about the end of March last, complaining of severe pricking pains on the dorsal surface of the left hand. Her mistress informed me that the girl was not at all fond of work, and that she had a deal of trouble to get her to do it; that since the hand had been bad, she would do nothing but sit down and cry. On examination of the hand I found it puffy and inflamed, and on asking if she felt the pricking sensation at any particular point, was referred to a spot in the centre of the hand. On touching this with my finger I distinctly felt something sharp and pointed. I used a pair of dressing forceps and extracted a full-sized sewing needle, which had been pushed obliquely into the flesh until the whole of it was out of sight. She could give no account of how it got there. Three evenings afterwards she was again brought in, and from the same place and in the same manner I extracted another needle. About a week after she came again, and this time I withdrew a pin (which had been pushed in until the head was covered) from the same place. A few days after she came again, with her hand (of course previously inflamed from her treatment of it) very œdematous and of a bright-blue colour, which I found she had produced by a liberal use of the blue bag and vinegar. I felt so disgusted with her that I advised her mistress to get rid of her at once, which was done, and the girl returned to the country. It seems hardly credible that a person of her age could be so cunning, and would inflict so much pain upon herself to avoid work.

Walthamstow.

The Infectious Diseases Notification ACT.At a meeting of the Council of the County Borough of Cardiff, held on Saturday, Nov. 9th, a resolution was passed "That the Infectious Diseases Notification Act, 1889, shall be adopted in the districts of the urban and port sanitary authorities respectively, and that the said Act shall come into operation on December 16th next." 